[Research Paper]

복합소재 고체 가연물의 화재 시 발생되는 열방출률의 FDS 예측 특성

\author{
남동군 · 홍터기 $\left.\right|^{*}$ 류명호 $*$ 박설현 $^{* * \dagger}$
}

한국소방산업기술원 기술연구소 책임연구원, *조선대학교 대학원 기계시스템.미래자동차공학과 대학원생,

**조선대학교 기계공학과 교수

\title{
Characteristics of Heat Release Rate Predictions of Fire by a Fire Dynamics Simulator for Solid Combustible Materials
}

\author{
Dong-Gun Nam $\cdot$ Ter-Ki Hong ${ }^{*} \cdot$ Myung-Ho Ryu ${ }^{*} \cdot$ Seul-Hyun Park ${ }^{* * \dagger}$ \\ Chief Researcher, R \& D Laboratory, Korea Fire Institute, \\ *Graduate Student, Dept. of Mechanical System \& Automotive Engineering Graduate School of Chosun University, \\ ${ }^{* *}$ Professor, Department of Mechanical Engineering, Chosun University
}

(Received August 15, 2020; Revised August 19, 2020; Accepted August 19, 2020)

\section{요 약}

복합소재 고체 가연물의 화재발생시 발생되는 열방출률을 ISO 9705 룸코너 시험을 통해 측정하였고 Fire dynamics simulator (FDS)에서 제공하는 열방출률 예측모델을 이용하여 전산해석을 수행하였다. 복합소재 고체 가연물로는 PU 폼과 $\mathrm{PP}$, 철재로 대부분 구성되어있는 영화관 의자를 선정하였다. FDS에서 제공되는 열방출률 예측방법을 단순모델 과 열분해 모델로 구분하고 각각의 모델을 적용하여 동일한 조건에서 전산 해석한 결과, 열분해 모델을 통해 예측된 열방출률과 화재성장율이 단순모델을 이용하는 경우에 비해 ISO 9705 룸 코너 시험을 통해 측정된 결과와 잘 일치함 을 확인할 수 있었다.

\section{ABSTRACT}

The heat release rate (HRR) of fire for solid combustibles, consisting of multi-materials, was measured using the ISO 9705 room corner test, and a computational analysis was conducted to simulate the fire using an HRR prediction model that was provided by a fire dynamics simulator (FDS). As the solid combustible consisted of multi-materials, a cinema chair composed primarily of PU foam, PP, and steel was employed. The method for predicting the HRR provided by the FDS can be categorized into a simple model and a pyrolysis model. Because each model was applied and computational analysis was conducted under the same conditions, the HRR and fire growth rate predicted by the pyrolysis model had good agreement with the results obtained using the ISO 9705 room corner test.

Keywords : Fire safety, Fire protection, Disaster prevention, Fire suppression, Fire science

\section{1. 서 론}

화재로 인해 발생되는 막대한 인적·물적 피해 손실은 건축물의 고층화로 점차 증가하는 추세이다. 특히 건축물 에서 일어난 화재의 경우, 화재의 성장 및 확산 등에 따라 구 조 활동에 큰 영향을 줄 수 있다. 건축물 화재 위험성을 판별 하기 위해 허용피난시간(Available safe egress time, ASET)과 소요피난시간(Required safe egress time, RSET)의 비교를 통 해 건축물의 안전성을 평가하는 성능위주설계(Performance- based design)가 시행되고 있다 ${ }^{(1-3)}$. 성능위주설계는 화재 위 험성이 높은 건축물에 대하여 화재 시나리오를 설정하고 소 요피난시간이 허용피난시간에 초과하지 않도록 설계하는 방 법(4)으로 피난 안전성을 예측하기 위해 화재 시 발생하는 열 방출률의 입력을 필요로 한다. 주어진 화재 시나리오에서 열 방출률의 예측은 주로 미국 표준기술연구소(National institute of standards and technology, NIST)에서 개발된 Fire dynamics simulator (FDS)를 통해 이루어지고 있다(5-6).

화재 시 발생되는 가연물의 열방출률(Heat release rate,

† Corresponding Author, TEL: +82-62-230-7174, FAX: +82-62-230-7171, E-Mail: isaac@chosun.ac.kr

(c) 2020 Korean Institute of Fire Science \& Engineering. All right reserved. 
$\mathrm{HRR}$ )을 정확히 예측하기 위해서는 단위 시간당 소모되는 연료의 질량(연료 소모율)과 가연물의 유효 연소열(Effective heat of combustion)의 입력이 필요하며 열방출률 예측에 관 련하여 FDS에서는 2 가지 입력 방식을 지원한다 ${ }^{(7)}$. 통상적 으로 사용되는 방법은 사용자가 시험을 통해 얻어진 가연 물의 연료 소모율을 미리 정의하는 방식으로 점화원에 의 해 가연물의 표면온도가 점화온도에 도달하면 정해진 연료 를 연소 환경과는 상관없이 소모하게 함으로써 열방출률을 계산한다. 또 다른 방법은 $\mathrm{FDS}$ 에 탑재된 열분해 모델( ${ }^{(8)}$ 을 통해 연료 소모율을 직접 계산하는 방식으로 FDS로 계산 된 가연물의 온도를 바탕으로 가연물의 열분해율을 조절함 으로써 직.간접적으로 환기 조건과 같은 연소환경을 반영 하여 열방출률을 예측할 수 있는 장점이 있다.

하지만 FDS에서 제공하는 열방출 예측모델은 극단적인 화재 시나리오에서 서로 다른 결과를 도출할 할 수 있다. 특히 화재 시 발생되는 열방출률을 예측하기 위해 사용자 가 고체 가연물 연료의 소모율을 정의하는 경우 대부분 공 기가 충분한 시험조건(Well-ventilated condition)에서 측정된 결과를 바탕으로 입력된 경우가 대부분이므로 밀폐되거나 환기 부족(Under-ventilated condition) 화재 시나리오에 적용 되는 경우 화재의 성장이나 최대 열방출률 관점에서 확연 한 차이를 보일 수 있다(). 이렇듯 FDS에서 제공되는 열방 출률 예측모델 간 특성에 따라 화재 성장 예측이 상이할 수 있지만, 열방출률 예측모델 상호 간의 차이점을 고찰한 연구 는 매우 제한적인 실정이다. 따라서 본 연구에서는 FDS에서 제공하는 2 가지 가연물의 열방출률 예측모델을 동일한 조건 에 적용하여 화재 성장 특성을 열방출률의 관점에서 고찰해 보고자 하였다. 이를 위해서 가연물로는 서로 다른 소재로 구성된 영화관 의자를 선정하였고 ISO 9705 룸 코너 시험 장치를 이용해 열방출률을 측정하고 FDS 열방출률 모델로 계산된 결과와 비교 분석하였다.

\section{2. 실험 및 전산해석 방법}

\section{1 실험방법 및 조건}

본 연구에서는 복합소재 고체 가연물의 열방출률을 측 정하기 위해 Figure 1에 도시된 ISO 9705 룸 코너 시험 장 치를 이용하였다. ISO 9705 룸 코너 시험 장치는 $2.4 \mathrm{~m} \times$ $3.6 \mathrm{~m} \times 2.4 \mathrm{~m}$ 크기의 구획 내부 벽면에서의 화재 전파 실 험(10)을 비롯하여 구획 환기 조건에 따른 화재 특성(11)을 측 정할 수 있도록 설계되어 있지만, 본 연구에서는 개방된 환 기 조건에서 복합소재 고체 가연물의 화재 시 발생되는 열 방출률을 측정하기 위해 구획 내부가 아닌 구획 바깥쪽 사 각 배기 후드 아래에서 실험을 진행하였다.

복합소재 고체 가연물로는 Figure 2에 도시된 영화관 의 자를 사용하였다. 총 질량 약 $33 \mathrm{~kg}$ 인 영화관 의자는 연소 시 반응하지 않는 철재와 소량의 목재를 제외하면 대부분 Polyurethane (PU) 폼과 Polypropylene (PP)로 구성되어있다.

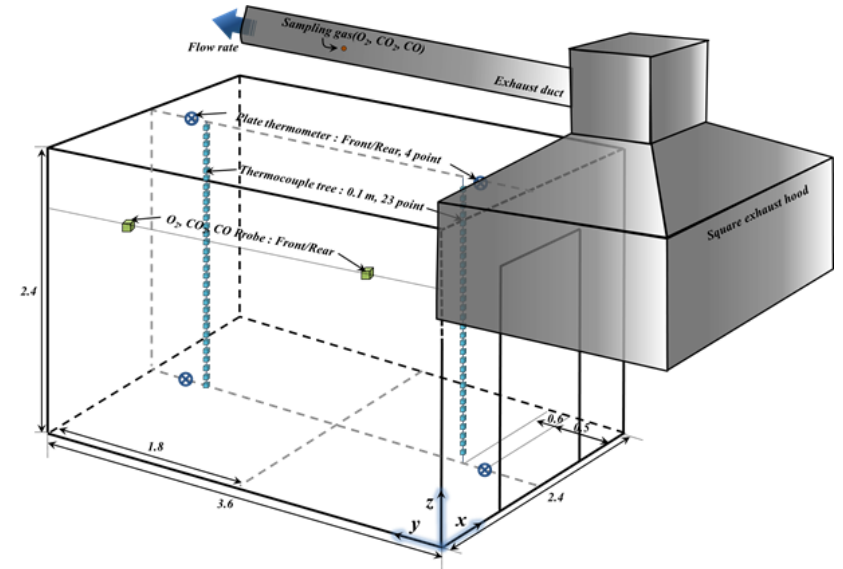

Figure 1. ISO 9705 Room corner tester.

영화관 의자는 표면적이 $0.1 \mathrm{~m} \times 0.1 \mathrm{~m}$ 인 헵탄 $\left(\mathrm{C}_{7} \mathrm{H}_{16}\right)$ 풀 (Pool) 버너를 의자 하단부에 설치하고 강제 점화하여 가연 물로 화염전파가 발생하도록 하였다. 복합소재 고체 가연물 로 구성된 영화관 의자의 화재 시 발생되는 열방출률은 배기 후드 덕트에서 산소농도를 측정하고 산소 소모열량법(12)을 이용하여 계산하였다.

\subsection{FDS 전산해석 방법 및 조건}

FDS (version 6.5.3) 전산해석을 통해 복합소재 고체 가연 물의 연소로 발생되는 열방출률을 예측하는 방식은 우선 Thermal gravimetric analysis (TGA) 분석이나 마이크로 칼로 리미터 등을 이용하여 가연물의 활성화 에너지(Activation energy), $\mathrm{E}$ 와 선인자 계수 (Pre-exponential factor), $\mathrm{A}$ 를 획득 하여 식(1)과 식(2)을 통해 계산하는 방법이다 ${ }^{(13)}$. 즉, 복합 소재 고체가연물을 구성하는 각각의 소재에 대해 획득된 $\mathrm{A}$ 와 $\mathrm{E}$ 를 입력하여 전체 가연물의 열분해율을 계산하고 유 효 연소열을 곱해 열방출률을 예측하는 방식이다. 본 연구 에서는 이러한 예측 방법을 열분해 모델로 지칭하였다.

$$
\begin{aligned}
& \dot{q}^{\prime \prime}=\dot{m}^{\prime \prime} \Delta H_{e}=\Delta H_{e} \rho_{0} \int_{0}^{L} \sum_{i}\left(1-\nu_{s, i}\right) A_{i}\left(\frac{\rho_{i}}{\rho_{0}}\right)^{n_{i}} \exp \left(\frac{-E_{i}}{R T(x)}\right) d x \\
& \rho_{s} c_{p, s} \frac{\partial T_{s}}{\partial t}=\frac{\partial}{\partial x}\left(k_{s} \frac{\partial T_{s}}{\partial x}\right)+\dot{q}_{s, r}^{\prime \prime \prime}+\dot{q}_{s, c}^{\prime \prime \prime}
\end{aligned}
$$

앞서 설명한 바와 같이 단위 면적당 열방출률 $\left(q^{\prime \prime}\right)$ 은 고체 가연물의 열분해를 통해 생성된 단위 면적 당 가연성 가스 발생 질량율 $\left(\dot{m}^{\prime \prime}\right)$ 과 유효 연소열 $\left(\Delta H_{e}\right)$ 로 계산할 수 있다. 이 때, 가연물의 온도는 깊이 방향 $(x)$ 의 1 차원 열전도 방정식 로 계산되며, $T_{s}$ 는 가연물의 온도, $t$ 는 시간, $\rho_{s}$ 은 가연물의 밀도, $c_{p, s}$ 는 가연물의 비열, $k_{s}$ 는 가연물의 열전도계수, $\dot{q}^{\prime \prime \prime}{ }_{s, r}$ 와, $\dot{q}^{\prime \prime \prime}{ }_{s, c}$ 은 생성 항을 의미한다.

다른 예측 방법으로는 ISO 5660 콘칼리미터 시험을 통 해 측정된 고체가연물의 단위 면적당 열방출률(Heat release rate per unit area, HRRPUA) 혹은 질량감소율(Mass loss rate 


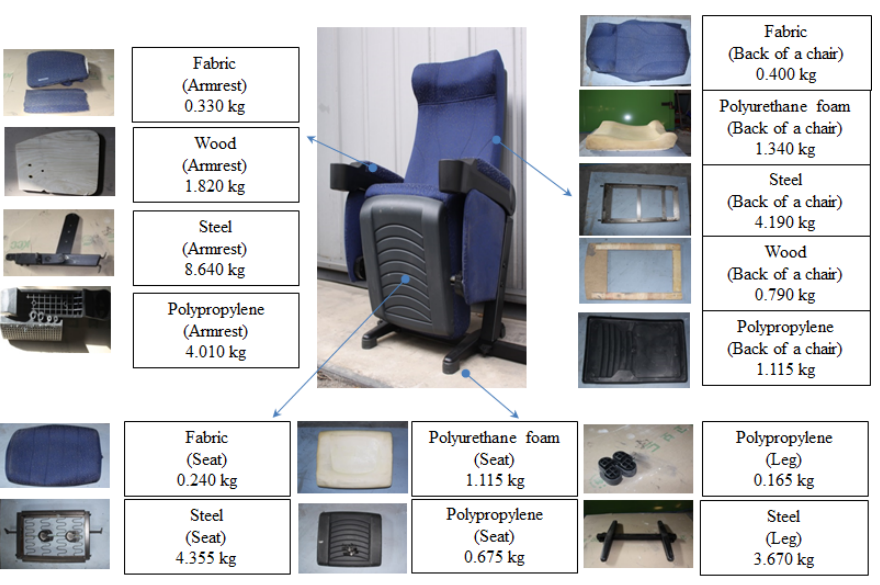

(a) Schematic of cinema chair

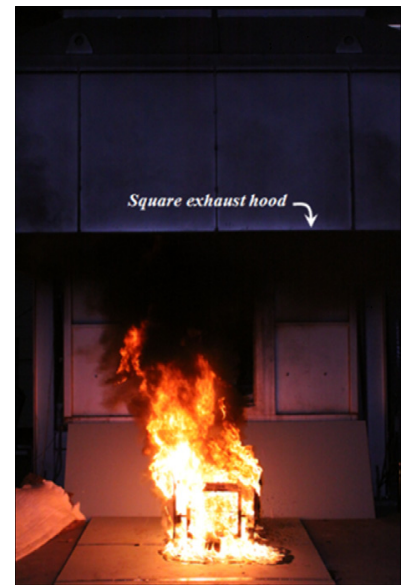

(b) Combustion experiment of cinema complex

Figure 2. ISO 9705 Room corner test of cinema complex.
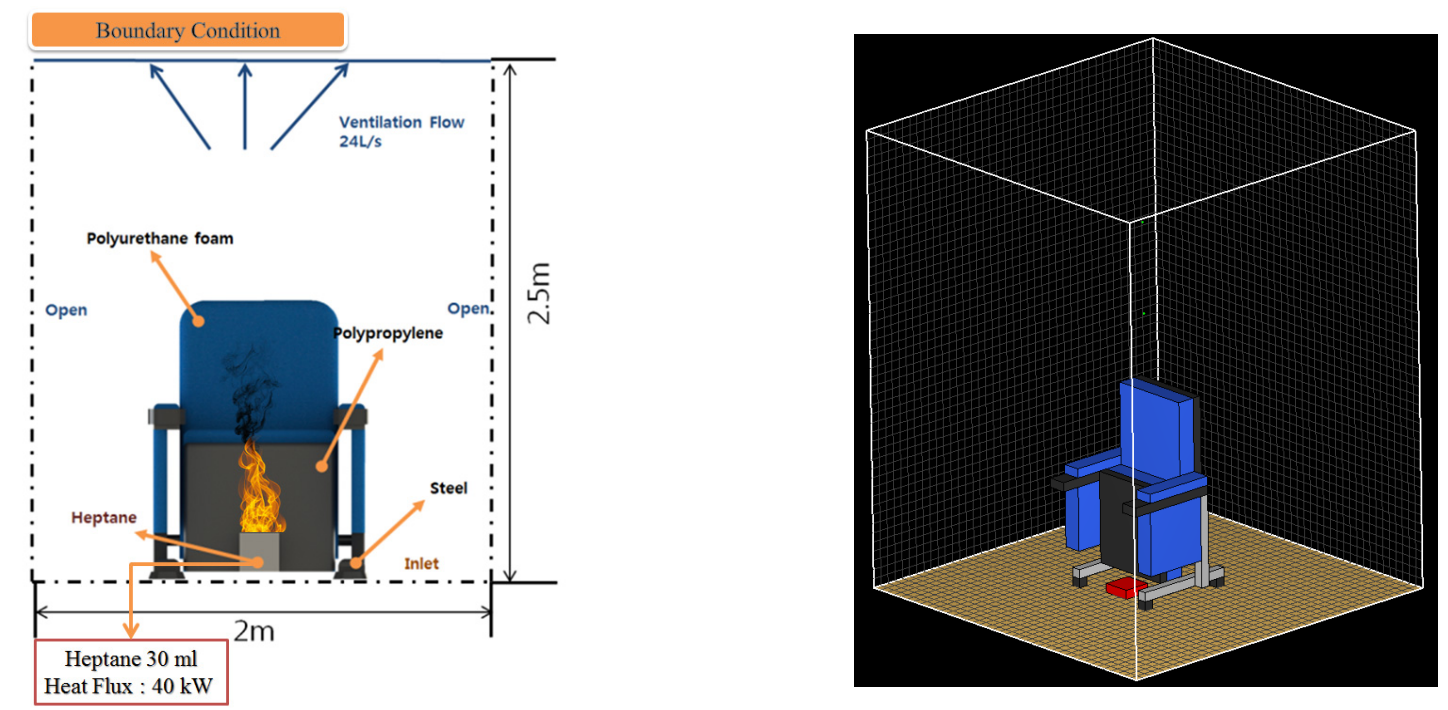

(a) Computational domain for the ISO 9705 room corner experiment (b) Mesh generated for the ISO 9705 room corner experiment Figure 3. Computational domain and mesh generated for the ISO 9705 room corner experiment.

per unit area, MLRPUA), 점화 온도, 유효 연소열을 복합소 재 고체 가연물을 구성하는 각각의 소재에 대해 입력하고 가연물의 점화 온도(Ignition temperature)에 도달하는 시점 부터 FDS에서 정의한 화염 소멸조건 ${ }^{(8)}$ 에 도달하는 순간까 지 입력된 열방출을 지속하는 방식이다. 본 연구에서는 이 러한 예측 방법을 단순 모델로 지칭하였다.

단순 모델의 경우 복합소재 고체 가연물을 구성하는 소 재에 대해 각각 열분해율을 따로 계산하지 않고 가연물 표 면 온도가 점화 온도에 도달하면 입력된 HRRPUA나 MLRPUA에 따라 가연 가스(연료)의 감소율이 결정되고 유 효 연소열을 고려하여 연소 현상을 모사하기 때문에 계산 시간이 빠르다는 장점이 있다. 하지만 선행 실험을 통해 해 석에 필요한 고체 가연물 별로 HRRPUA나 MLRPUA 직접 측정하거나 이를 제공하는 데이터 베이스(14)가 필요하다는 단점이 있다. 아울러 ISO 5660 콘칼리미터 시험과 같이 특
정 연소 조건에서 획득된 HRRPUA나 MLRPUA를 사용하 기 때문에 연소 조건(환기 조건 등)이 상이한 화재환경에 열방출률을 예측하는 경우에는 상당한 오차를 발생시킬 수 도 있다. 이에 반해 열분해 모델의 경우, 화재환경으로부터 전달되는 열유속을 바탕으로 계산된 가연물의 표면 온도를 이용하여 열분해율을 직접 결정하기 때문에 단순 모델에 비해 계산 시간이 상대적으로 많이 소요되는 단점이 있지 만, 가연물의 표면 온도와 활성화 에너지 등을 종합적으로 고려하여 능동적인 열방출률 계산이 가능하다.

Figure 3(a), (b)는 ISO 9705 룸 코너 시험의 FDS 전산해 석에 적용된 영화관 의자의 형상과 계산영역을 도시한 그 림이다. $2,000(\mathrm{~W}) \times 2,000(\mathrm{~L}) \times 2,500(\mathrm{H}) \mathrm{mm}$ 크기의 계산 공간에서 ISO 9705 룸 코너 시험과 동일하게 $40 \mathrm{~kW}$ 급 헵 탄 풀 버너를 동일한 점화원으로 지정하였고 개방된 상태 로 가연물 상층부에 동일한 덕트 유속 조건을 적용하였다. 
Table 1. Summary of Thermal and Decomposition Properties of PU Foam \& $\mathrm{PP}^{(14)}$

\begin{tabular}{|c|c|c|c|c|c|c|c|}
\hline & \multicolumn{4}{|c|}{ Simple model } & \multicolumn{3}{|c|}{ Pyrolysis model } \\
\hline \multicolumn{8}{|c|}{ Material thermal properties: } \\
\hline & \multicolumn{3}{|c|}{ PU foam } & \multicolumn{2}{|r|}{ PP } & \multicolumn{2}{|l|}{ Steel } \\
\hline Thermal conductivity, $\mathrm{k}\left(\mathrm{W} / \mathrm{m} \cdot{ }^{\circ} \mathrm{C}\right)$ & \multicolumn{3}{|c|}{0.03} & \multicolumn{2}{|r|}{0.22} & \multicolumn{2}{|l|}{45.8} \\
\hline Specific heat, $\mathrm{C}_{\mathrm{p}}\left(\mathrm{kJ} / \mathrm{kg} \cdot{ }^{\circ} \mathrm{C}\right)$ & \multicolumn{3}{|c|}{1.47} & \multicolumn{2}{|r|}{1.92} & \multicolumn{2}{|l|}{0.46} \\
\hline Density, $\rho\left(\mathrm{kg} / \mathrm{m}^{3}\right)$ & \multicolumn{3}{|c|}{17} & \multicolumn{2}{|r|}{950} & \multicolumn{2}{|l|}{7,850} \\
\hline \multicolumn{8}{|c|}{ Material decomposition properties : } \\
\hline & \multicolumn{2}{|c|}{ PU foam } & \multicolumn{2}{|c|}{ PP } & & PU Foam & PP \\
\hline Heat of combustion, $\Delta \mathrm{H}_{\text {comb }}(\mathrm{kJ} / \mathrm{kg})$ & \multicolumn{2}{|c|}{20,040} & \multicolumn{2}{|c|}{28,914} & \multirow{7}{*}{$\begin{array}{c}\text { Activation Energy, E } \\
(\mathrm{kJ} / \mathrm{kmol})\end{array}$} & \multirow{7}{*}{$1.49 \times 10^{5}$} & \multirow{7}{*}{$1.78 \times 10^{5}$} \\
\hline Ignition temperature $\left({ }^{\circ} \mathrm{C}\right)$ & \multicolumn{2}{|c|}{203.1} & \multicolumn{2}{|c|}{433.4} & & & \\
\hline \multirow{13}{*}{ Heat release rate per area $\left(\mathrm{kW} / \mathrm{m}^{2}\right)$} & Time (s) & Value & Time (s) & Value & & & \\
\hline & 0 & 0 & 0 & 0 & & & \\
\hline & 8 & 2.1 & 77 & 23.6 & & & \\
\hline & 11 & 85.5 & 144 & 274.4 & & & \\
\hline & 15 & 158.6 & 356 & 490.2 & & & \\
\hline & 18 & 187.9 & 443 & 519.4 & \multirow{8}{*}{$\begin{array}{c}\text { Pre-exponetial factor, A } \\
(1 / \mathrm{s})\end{array}$} & \multirow{8}{*}{$1.1 \times 10^{10}$} & \multirow{8}{*}{$3.04 \times 10^{10}$} \\
\hline & 21 & 164.0 & 500 & 637.3 & & & \\
\hline & 28 & 70.6 & 623 & 777.5 & & & \\
\hline & 40 & 35.8 & 656 & 940.8 & & & \\
\hline & 60 & $\begin{array}{l}10.1 \\
\end{array}$ & 700 & 994.7 & & & \\
\hline & 108 & 0 & 800 & 462.6 & & & \\
\hline & & & 932 & 118.3 & & & \\
\hline & & & 1170 & 0 & & & \\
\hline
\end{tabular}

아울러 본 연구에서는 영화관 의자의 구성 소재 중, 대부분 을 차지하는 PP와 PU 폼, 철재로 단순화하여 해석을 진행 하였다. 식(3)의 계산한 특성 화재 직경 (Characteristic fire diameter, $\left.D^{*}\right)^{(15)}$ 을 이용하여 계산한 $\left(D^{*} / \bar{\triangle}\right)$ 은 15.6 으로 2 가 지 열방출률 예측 모델 적용된 $\mathrm{FDS}$ 전산해석에 동일하게 적용되었다.

$$
D^{*}=\left(\frac{\dot{Q}}{\rho C_{p} T_{\infty} \sqrt{g}}\right)^{\frac{2}{5}}
$$

식(3)에서 $\dot{Q}$ 는 발열량, $\rho$ 는 주변 공기의 밀도, $C_{p}$ 는 정압 비열, $T_{\infty}$ 는 외기 온도를 의미하며, 열방출률 예측을 위한 해석공간에 적용된 해석 격자수는 총 80,000 개다. 아울러 FDS 열방출률 전산해석에 적용된 복합소재의 열물성치을 비롯한 열분해 물성 값은 Table 1에 정리되어 있다.

\section{3. 결과 및 고찰}

Figure 4(a), (b)는 동일한 점화와 격자 조건에서 FDS의 단순 모델과 열분해 모델을 이용하여 PU 폼과 PP로 구성 된 영화관 의자 화재를 시뮬레이션한 결과와 열방출률을 도시한 결과이다. 그림에서 볼 수 있는 바와 같이 FDS 전 산해석 결과, 단순모델이 열분해 모델에 비해 초기 화재 성
장이 다소 빠른 것을 확인할 수 있으며, 두 모델을 통해 예 측된 최대 열방출률은 모두 비슷하지만, 실제 ISO 9705 룸 코너 시험 장치로 측정된 최대 열방출률에 비해 과다 예측 하고 있음을 확인할 수 있다. 이는 선행 연구결과(16)에서도 보고된 바와 같이 실제 폴리머 계열의 소재가 다량 포함되 어있는 고체 가연물은 화재 진행 과정에서 소재의 일부가 본 가연물에서 이탈되어 바닥에 떨어짐으로써 열방출률이 줄어들 수 있지만, FDS 전산해석에서는 이러한 현상을 재 현할 수 없어 나타나는 결과로 판단된다.

아울러 단순모델의 경우에는 실제 ISO 9705 룸 코너 시 험 장치로 측정된 열방출률과 열분해 모델로 계산된 열방 출률에서 나타나는 두 개의 열방출률 피크가 관찰되지 않 은 것을 확인할 수 있다. 이는 선행 연구결과(17)에서 보고 된 바와 같이 $\mathrm{PU}$ 폼과 $\mathrm{PP}$ 의 활성화 에너지의 차이로 인해 발생한 열분해율의 차이가 주된 영향으로 판단된다. 즉, 점 화 직후에 활성화 에너지가 낮은 소재인 $\mathrm{PU}$ 폼의 빠른 열 분해율로 인해 연소 반응이 빠르게 개시되고 PU 폼에 비해 활성화 에너지가 큰 소재인 $\mathrm{PP}$ 는 상대적으로 느린 열분해 율로 인해 연소 반응이 느리게 진행되기 때문으로 판단된 다. 결국, 열분해 모델의 경우에는 각 소재별 열분해 물성 이 반영되고 가연물의 표면 온도에 따라 열분해 속도가 조 절되기 때문에 ISO 9705 룸 코너 시험 장치로 측정된 열방 출률을 비교적 잘 모사하고 있지만, 단순 모델의 경우에는 


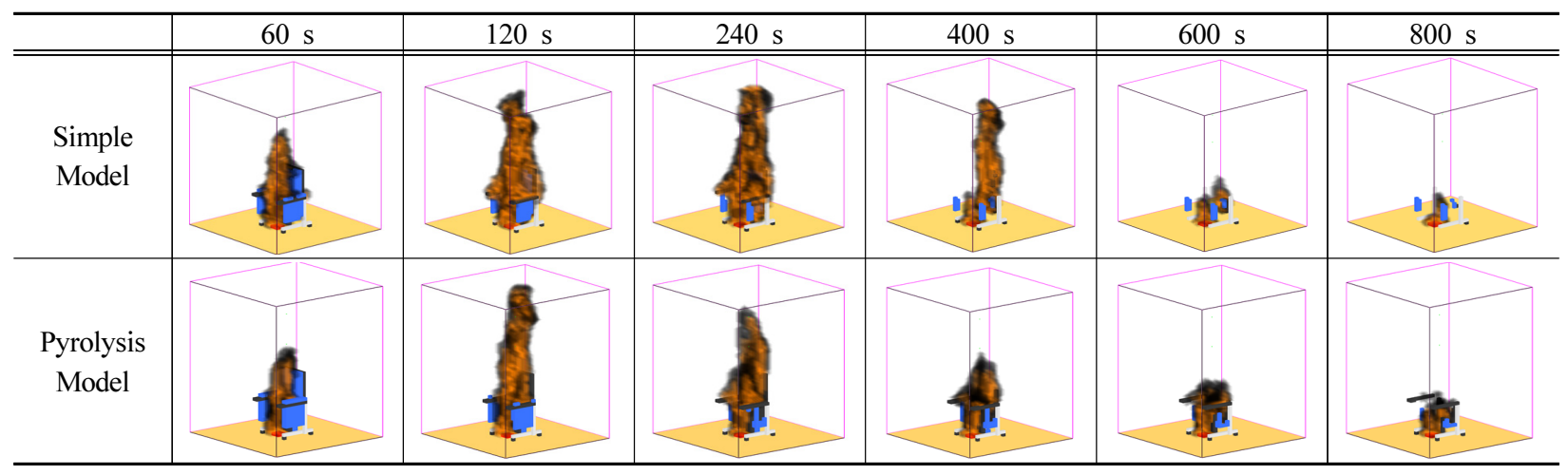

a) Sequential images of burning a cinema chair obtained from the FDS analysis

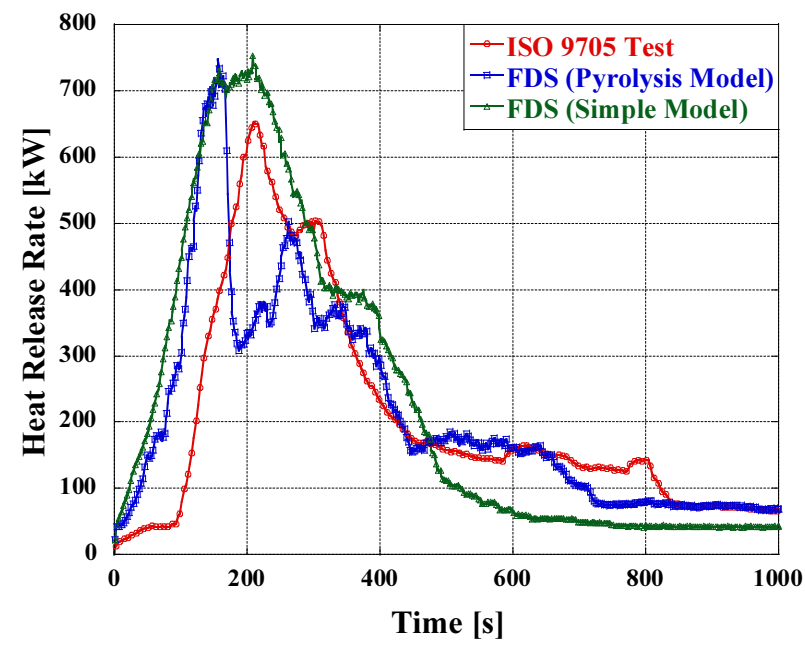

b) Measured and calculated HRR plotted as a function time

Figure 4. Comparisons of heat release from burning a cinema chair.

가연물의 열분해를 고려하지 않고 점화 초기 시 화염으로 부터 발생된 높은 열유속에 의해 순간적으로 PU 폼와 PP 소재의 점화 온도에 도달하고 이후 정의된 열방출(연료 소 모)에 의해 화재 현상을 예측하기 때문에 열방출률을 정확 히 예측하는데 한계가 존재한다.

Figure 5은 영화관 의자의 화재로 발생된 총 열방출(Total heat release, THR)을 비교한 결과이다. ISO 9705 룸 코너 시 험 결과가 $228.69 \mathrm{MJ}$ 로 가장 적었고, FDS 열분해 모델로 예측된 결과가 $239.98 \mathrm{MJ}$ 과 $\mathrm{FDS}$ 단순 모델로 예측된 결과 가 $257.97 \mathrm{MJ}$ 로 시험 결과 대비 열분해 모델은 약 $5 \%$, 단 순 모델은 약 $12.8 \%$ 로 열분해 모델이 ISO 9705 룸 코너 시 험 결과와 가장 가까운 결과를 예측하였다. 이는 앞서 기술 한 FDS의 열분해 모델이 단순 모델의 차이를 잘 반영한 결 과이다.

화재 발생 시 피난 안전성을 평가는 식(5)에 제시된 화재 성장률과 밀접한 상관관계를 갖는다 ${ }^{(18)}$. 화재 성장률은 가 연물의 열방출률 곡선에서 점화 시점을 원점으로 하여 최 대 열방출률을 연결하는 근사 곡선으로 정의할 수 있다 ${ }^{(19)}$.

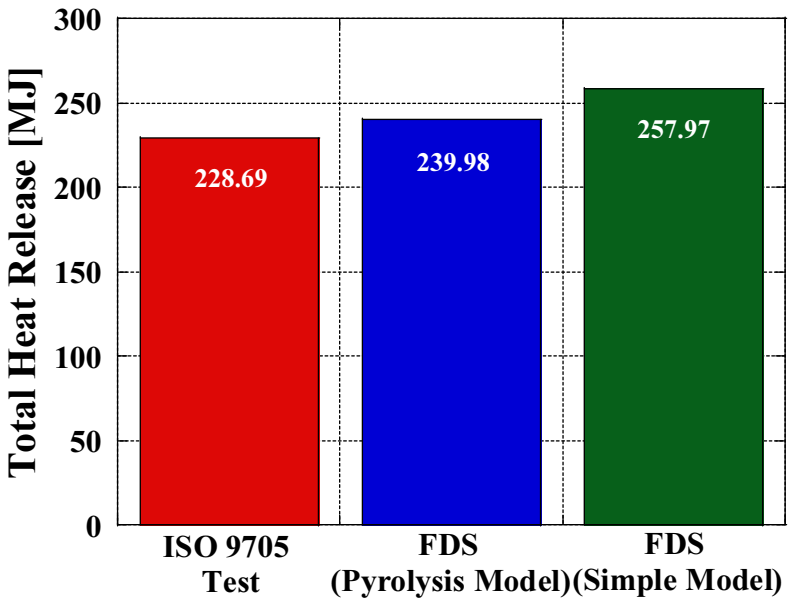

Figure 5. THR comparisons between room corner experiment and FDS simulation.

$\dot{q}_{\max }^{\prime \prime \prime}=\alpha t^{2}$

식(5)에서 $\dot{q}^{\prime \prime \prime}{ }_{\text {max }}$ 는 최대 열방출률, $t$ 는 최대 열방출률에 도달 시간을 의미하고 $\alpha$ 는 화재성장 계수로 화재 시나리오 
Table 2. Values for $\alpha$ and tg for Different Growth Rates ${ }^{(19)}$

\begin{tabular}{c|c|c}
\hline Fire growth rate & NFPA 72 & $\alpha\left(\mathrm{kW} / \mathrm{s}^{2}\right)$ \\
\hline \hline Slow & $\mathrm{t}_{\mathrm{g}} \geq 400 \mathrm{~s}$ & $\alpha \leq 0.0066$ \\
\hline Medium & $150 \leq \mathrm{t}_{\mathrm{g}}<400 \mathrm{~s}$ & $0.0066<\alpha \leq 0.0469$ \\
\hline Fast & $\mathrm{t}_{\mathrm{g}}<150 \mathrm{~s}$ & $0.0469<\alpha \leq 0.1876$ \\
\hline Ultra-fast & $\mathrm{t}_{\mathrm{g}} \leq 75 \mathrm{~s}$ & $\alpha>0.1876$ \\
\hline
\end{tabular}

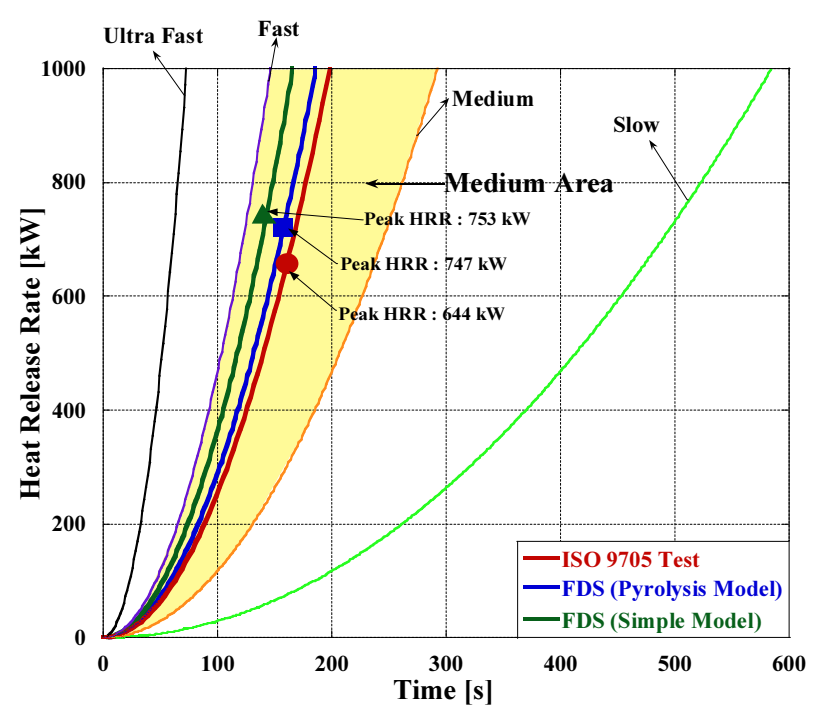

Figure 6. Fire growth curves comparisons between room corner experiment and FDS simulation.

에서 화재성장율를 정의할 수 있다. NFPA 72에서는 착화 가 발생하는 시점부터 열방출률이 $1.055 \mathrm{MW}$ 까지 성장하 는 걸리는 시간 $\left(t_{q}\right)$ 을 이용해 화재성장율을 분류한다(20,21). Table 2에는 NFPA 72에서 정의하는 화재성장율의 단계와 화재성장 계수가 정리되어 있다.

Figure 6은 NFPA 72의 화재성장율 분류 방법을 기준으 로 ISO 9705 룸 코너 시험의 열방출률 결과와 FDS 열분해 모델 및 단순 모델의 열방출률 계산 결과를 화재성장곡선 으로 도시하여 비교한 그래프이다. 그림에서 볼 수 있는 바 와 같이 화재성장은 시험 및 해석 결과가 Medium 영역에 속하는 것을 확인 할 수 있다. 하지만 Table 3에서 볼 수 있 듯이 ISO 9705 룸 코너 시험 결과의 화재성장 계수는 0.025 로 열분해 모델를 이용하여 계산한 결과(0.028)가 단순모델 을 이용하여 계산한 화재성장 계수(0.036)에 비해 비교적 더 잘 일치하는 것을 확인할 수 있다.

\section{4. 결 론}

본 연구에서는 ISO 9705 룸 코너 시험 장치를 이용하여 $\mathrm{PU}$ 폼과 $\mathrm{PP}$, 철재로 구성된 복합소재 고체 가연물인 영화 관 의자의 화재 시 발생되는 열방출률을 측정하였다. 아울 러 ISO 9705 룸 코너 시험의 FDS 전산해석 수행을 통해 영 화관 의자의 열방출률을 계산하고 ISO 9705 룸 코너 시험
Table 3. Summary of Fire Growth Rate Calculated from Experiments and FDS Simulations

\begin{tabular}{c|c|c|c}
\hline Fire growth rate & Growth $(\mathrm{s})$ & Peak HRR $(\mathrm{kW})$ & $\alpha\left(\mathrm{kW} / \mathrm{s}^{2}\right)$ \\
\hline \hline ISO 9705 test & 151 & 644 & 0.025 \\
\hline Pyrolysis model & 144 & 747 & 0.028 \\
\hline Simple model & 131 & 753 & 0.036 \\
\hline
\end{tabular}

을 통해 획득된 결과와 비교하여 다음과 같은 결론을 얻을 수 있었다.

1) FDS에서 제공되는 열방출률 예측방법을 단순모델과 열분해 모델로 구분하고 각각의 모델을 적용하여 복합소재 고체 가연물인 영화관 의자의 화재를 동일한 조건에서 전 산 해석한 결과 열분해 모델을 통해 예측된 열방출률이 단 순모델을 이용하는 경우에 비해 ISO 9705 룸 코너 시험을 통해 측정된 열방출률과 잘 일치함을 확인할 수 있었다.

2) 아울러 단순모델을 이용하여 영화관 의자의 열방출률 을 예측하는 경우 ISO 9705 룸 코너 시험을 통해 측정된 두 번의 열방출률 피크를 예측하지 못하였지만, 열분해 모 델을 이용한 경우 시험을 통해 측정한 열방출률과 유사하 게 두 번의 피크를 관찰할 수 있었다.

3) 단순모델을 이용하여 획득된 열방출률로부터 도출된 화재성장율은 ISO 9705 룸 코너 시험 결과에 비해 과다 예 측되었으며 열분해 모델로부터 계산한 화재성장율이 비교 적 ISO 룸 코너 시험 결과와 잘 일치하였다.

4) 결국, 각 소재별 열분해 물성이 반영되고 가연물의 표 면온도에 따라 열분해 속도를 조절하는 열분해 모델이 ISO 9705 룸 코너 시험 장치로 측정된 열방출률 및 화재 성장 률을 비교적 잘 예측하는 것으로 판단된다.

\section{후 기}

본 연구는 소방청 현장중심형 소방활동지원 기술개발사 업(MPSS-소방안전-2015-66)의 연구비 지원과 한국항공우주 연구원(과제번호: 171111560)의 지원을 받아 수행된 연구임.

\section{References}

1. K. H. Kim, S. H. Lee, H. Y. Kim, T. H. Song and B. K. Jin, "Establishment of Building Fire Safety System Improvement of Building Fire Safety Regulations", KICT 2000-082, Korea Institute of Construction Technology, pp. 31-37 (2000).

2. H. S. Han and C. H. Hwang, "Study on the Available Safe Egress Time (ASET) Considering the Input Parameters and Model Uncertainties in Fire Simulation", Fire Science and Engineering, Vol. 33, No. 3, pp. 112-120 (2019).

3. H. S. Yun and C. H. Hwang, "Analysis of Prediction Results and Grid Size Dependence According to Changes in Fire Area", Fire Science and Engineering, Vol. 33, No. 6, 
pp. 9-19 (2019).

4. W. Jahn, G. Rein and J. Torero, "The Effect of Model Parameters on the Simulation on Fire Dynamics", Fire Safety Science-Proceedings of the Ninth International Symposium, pp. 1341-1352 (2008).

5. K. H. Jang, "Proposals on the Input Data Standardization Needs of Fire and Evacuation Simulation in Performance Based Design", Fire Science and Engineering, Vol. 30, No. 5, pp. 18-25 (2016).

6. H. Y. Jang, C. H. Hwang, C. B. Oh and D. G. Nam, "Evaluation of Design Fire Curves for Single Combustibles in a Cinema Complex", Fire Science and Engineering, Vol. 34, No. 3, pp. 18-27 (2020).

7. T. K. Hong, "A Study of Thermal Pyrolysis and Burning Characteristics of Non-charring Solid Combustible with a Cone Calorimeter", Master's Thesis, Chosun University (2008).

8. K. McGrattan, S. Hostikka, R. McDermott, J. Floyd, C. Weinschenk and K. Overholt, "Fire Dynamics Simulator, Technical Reference Guide, Volume 1: Mathematical Model”, NIST SP 1018-1, NIST, Gaithersburg, MD (2015).

9. T. K. Hong, D. P. Seo and S. H. Park, "Experimental Study on the Effect of Flow around Solid Combustibles and Thermal Thickness on Heat Release Rate Characteristics", Fire Science and Engineering, Vol. 34, No. 3, pp. 28-34 (2020).

10. ISO/TC 92, "Reaction to Fire Tests - Room Corner Test for Wall and Ceiling Lining Products - Part 1: Test Method for a Small Room Configuration", ISO 9705-1:2016(en) (2016).

11. NFPA 921, "Fire and Explosion Investigation Guide", National Fire Protection Association, Quincy, MA, USA (2017).
12. C. Huggett, "Estimation of the Rate of Heat Release Rate by Means of Oxygen Consumption", Journal of Fire and Flammability, Vol. 12, pp. 61-65 (1980).

13. K. McGrattan, S. Hostikka, R. McDermott, J. Floyd, C. Weinschenk and K. Overholt, "Fire Dynamics Simulator User's Guide", NIST SP 1019, Sixth Edition., NIST, Gaithersburg, MD (2015).

14. "Fire Technology Solution DB", http://www.kfiredb.com.

15. NRC and EPRI, "Verification and Validation of Selected Fire Models for Nuclear Power Plant Applications", NUREG1824 and EPRI 1011999, Final Report (2007).

16. S. C. Kim, "Feasibility Study on the Fire Scenario Design of a Couch Burning through a Fire Spread Model", Fire Science and Engineering, Vol. 30, No. 6, pp. 37-42 (2016).

17. T. K. Hong, J. W. Lee and S. H. Park, "Influences of Changes in the Thermal Properties on Pyrolysis of Solid Combustibles", Fire Science and Engineering, Vol. 31, No. 3, pp. 41-48 (2017).

18. Society of Fire Protection Engineers, "SFPE Handbook of Fire Protection Engineering", 3rd Edition, National Fire Protection Association, Quincy, MA, pp. 3-347 (2010).

19. W. Y. Walter and W. K. Chow, "A Monte Carlo Approach for the Design of Thermal Fire Detection System", NFPA - Fire Technology, Vol. 41, No. 1, pp. 93-104 (2005).

20. NFPA 92B, "Standard for Smoke Management Systems in Malls, Atria, and Large Spaces, 2009 Edition”, National Fire Protection Association, Quincy, MA, USA (2009).

21. NFPA 72, "National Fire Alarm and Signaling Code", National Fire Protection Association, Quincy, MA, USA (2017). 